\title{
Islam, MENA Region and Research Methods
}

\section{Islam: región MENA y métodos de investigación}

\author{
Deina Abdelkader ${ }^{1}$ \\ University of Massachusetts Lowell (EE.UU.)
}

Recibido: 15-12-18

Aprobado: 06-01-19

\begin{abstract}
The distinction between normative and objective knowledge and how social scientist imagine that their research is solely built on objectivity is currently being challenged especially in the political science field. If we take culture as an example and more specifically the question of identity and identity politics in the Middle East, we will find that the current modus operandi in political science research is distancing itself from objective knowledge because of the increased focus in the field on quantification. Whether one analyzes the work of Telhami on Identity in the Middle East, or Lynch's “The Arab Uprisings Explained", one will find that they all reflect on the academic conundrum that the field is facing.
\end{abstract}

Key-words: MENA Region, Scientific Knowledge, Methodologism, Rationality.

${ }^{1}$ (Deina_Abdelkader@uml.edu)Associate Professor in the Political Science Department, a Visiting Scholar at the Center for Middle Eastern Studies, Harvard University (2016-current), previously a Visiting Scholar at Alwaleed Islamic Studies Program, Harvard University (2014-2016). She is the author of Social Justice in Islam (2000) and Islamic Activists: The Anti-Enlightenment Democrats (2011). She has also authored a number of articles, including "Coercion, Peace and the Issue of Jihad" in the Digest of Middle East Studies, and a book chapter, "Modernity, Islam and Religious Activism", in The New Global Order and the Middle East. Abdelkader served as the chair of the Religion and International Relations Book Award for the Religion and International Relations Section of the International Studies Association (2015), and she is one of two women on the North American Muslim Jurisprudential Council. Abdelkader is a co-founder and co-director of the Cohort for the Study of Islam and International Relations (COIRIS). Her areas of foci are: democratic transitions in the Muslim World, and Islamic Political Activism.

Araucaria. Revista Iberoamericana de Filosofia, Politica, Humanidades y Relaciones Internacionales, año $21, \mathrm{n}^{\circ} 41$. Primer semestre de 2019. Pp. 515-525. ISSN 1575-6823 e-ISSN 2340-2199 doi: 10.12795/araucaria.2019.i41.24 


\section{Resumen}

La distinción entre el conocimiento normativo y el conocimiento objetivo, así como el modo en que los científicos sociales imaginan su investigación en términos o no de objetividad, es algo que viene discutiéndose actualmente, especialmente en el campo de la ciencia política. Considerando la cultura y, más específicamente, la cuestión de la identidad y las políticas de identidad en Oriente Medio, encontramos que el modus operandi actual en la investigación de la ciencia política se está alejando del conocimiento objetivo debido al mayor enfoque en el campo de la cuantificación. Si uno analiza el trabajo de Telhami sobre Identidad en Oriente Medio, o bien las razones de los llamados "levantamientos" árabes de Lynch, encontrará que todos ellos cuestionan el rango académico del campo de estudio.

Palabras-clave: Región MENA-Conocimiento Científico-Metodologismo - Recaionalidad.

\section{Introduction}

Students in any field of study and especially in the humanities and social sciences are constantly reminded that the way they formulate their research question is half (if not more) of the effort of the research itself. Currently in the MENA region especially after the "Arab Spring" and the rise of ISIS as a phenomenon, the quest for finding adequate theories about social movements, demonstrations, and religious extremism are all begging to be answered. However, because the field of political science is going through a seismic shift, one of the main social science fields is incapable of researching the changes the MENA region is going through. Generally speaking resarch is conducted to: 1) Enrich/explain what is currently (or recently) happening, 2) to be able to better comprehend/predict what the future holds, given what's happening in real time.

This contemporary seismic shift in the political science field will undoubtedly create a lack in current explanations of the MENA region's political happenings, and it will also create a gap in the field's ability to predict with any agree of certainty what the future holds politically for the region. Therefore, on the academic level there is a huge lag, but also in terms of policy formulations the research will lead to political decisions and reactions to the region, that are far from the reality on ground. 


\title{
2. The Contemporary Scene in the Political Science Field in the United States
}

The literature examined in this section ranges from contributors looking at the field from another field's perspective; namely the legal field, to two subfields in political science: comparative democratization and security studies.

First, James Gardner's examination of political science as a legalist signifies and emphasizes that like culture, the issue of "morality" and citizenship cannot be quantified. He discusses: "First, some have criticized political science for adopting a reductive and improperly limited conception of political knowledge." (Gardner: 1146) James uses Isaiah Berlin's ${ }^{2}$ work to emphasize that human interactions cannot be reduced to quantification, that abstraction and analysis are qualities needed in research that addresses issues like: "statesmanship", for example. (Gardner, 1146) Gardner also points out that Leo Strauss's criticism" ${ }^{3}$, that: "only scientific knowledge is genuine knowledge. From this it immediately follows that all awareness of political things that is not scientific is cognitively worthless." (Gardner, 1147)

Last but not least, on the issue of "scientific knowledge", Gardner writes:

\begin{abstract}
"Because it aspires to be scientific political science seeks to apply itself to objective data. But for data to be objective, it must be measurable. Consequently, political science must confine itself to the analysis not merely of "measurable phenomena" but of phenomena that are measurable by the tools of political science" (Gardner: 1147-1148) ${ }^{4}$
\end{abstract}

The second issue of concern that Gardner highlights is the issue of "objectivity" where all things that are quantified are "scientific" and therefore "objective":

\begin{abstract}
"The goal of political science is not merely to understand political behavior, but through the identification of scientific laws of politics, to predict it. Indeed, in the scientific study of any subject there is no meaningful difference between understanding and prediction, for the ultimate measure of the validity of any scientific knowledge is its ability to predict-to know is to verify and to verify is to predict" (Gardner, 1151)
\end{abstract}

${ }^{2}$ Gardner quotes Berlin: "Sciences and theories cannot be even a partial substitute for a perceptual gift, for a capacity for taking in the total pattern of a human situation, of the way in which things hang together-a talent to which, the finer, the more uncannily acute it is, the power of abstraction and analysis seems alien, if not positively hostile" (Gardner, 1146)

3 "The break with the common sense understanding of political things compels the new political science to abandon the criteria of relevance that are inherent in political understanding. Hence, the new political science lacks orientation regarding political things; it has no protection whatever, except by surreptitious recourse to common sense, against losing itself in the study of irrelevancies" (Gardner, 1147)

${ }^{4}$ Using Berns, Gardner exemplifies his point further: " the sacrifice of political relevance on the alter of methodology. The questions asked and pursued are determined by the limits of the scientific method rather than by the subject matter" (Gardner, 1148). 
This inability to predict is a huge obstacle for the subfields mentioned earlier in the introduction: social movement theories, democratization and security studies. Gardner utilizes Habermas' comment of the plight of contemporary social sciences: "observers who seek to be objective and neutral deliberately blind themselves both to the considerations that motivate people within the system to act, and to the meanings with which the actual participants invest their actions" (Gardner, 1149). Thus both, Gardner and Habermas' comments are extremely relevant if one examines the Arab Barometer dataset, and how it analyzes the "Arab Spring's" causes and end results.

Gardner sums up his argument by stating:

" It does not necessarily follow, however, that the political scientist's results demonstrate anything significant about the norm under study; all political science shows in this situation-all it can ever show- is achievement or nonacheivement of the proxy measure that the political scientist has chosen to stand in for the norm's own validating conditions. This is precisely what Bern meant when he referred to "the sacrifices of political relevance on the altar of methodology" (Gardner, 1163-1164).

Gardner's main concerns are elections, electoral politics and the law, which he later emphasizes in his critique of political science methods. He writes that the field analyzes the "norm" of elections through a lens that constrains this "norm" because political scientists are limiting their scope of vision to this single lens. ${ }^{5}$

\section{B. Security Studies and "Methodologism" by Steven Van Evera}

As a specialist in the political science subfield of security studies, Evera defines what "methodologism" means: "An overdone focus on methodological techniques, especially techniques for measuring causal relationships. This focus has come at the expense of concern for other elements of successful social science" (Evera, Director's Statement, 1)

Evera clearly states his concern over his subfield:

"This cult of irrelevance is a special concern for security studies. Policy relevance is a central value of the security studies research. A political science field that discounts relevance is an uneasy home for security studies." (Evera, 2)

Not only is Evera concerned over the field's deterioration but he also warns that:

5 "This paradox arises because political science here purports to assess the existence of a norm by investigating a set of norm-validating conditions that are defined for their ease of measurement, and consequently for the convenience of the political scientist, rather than by the norm under study or by the enterprise that generated the norm in the first place" (Gardner, 1165) 
" The rise of methodologism is an important cause of the drift from relevance in political science. It also fosters empirical sterility and theoretical stagnation."

"A second deleterious trend in political science is seen in a rising claim that a particular method-large-n, or quantitative analysis- is superior to other methods, especially to qualitative, or case study methods" (Evera, 2)

Evera's concerns highlight the seismic shift in the field, but also emphasizes that there are specific subfields where "methodologism" hampers or transgresses other methods of research. ${ }^{6}$

In Evera's statement he highlights another important factor that directly relates to regionalists and research in the MENA region specifically: namely that there is a "polarization" in research methods between Americanists or scholars of American Politics and International Relations/Comparative Politics scholars:

"a 2009 survey found that 68 percent of IR scholars in the United States use mainly qualitative methods in their work, while 23 percent use mainly quantitative methods, and 2 percent use mainly formal modeling. Only 4 percent of articles in International Security from the 1990s used statistical methods." (Evera, 3)

As Evera stresses, the majority of researchers use qualitative methods, however, currently researchers utilize what is called mixed methods: a combination of qualitative and quantitative methods.

The overflow from the Americanists' research methods into International Relations is causing the seismic shift mentioned previously. If one could run a statistical test that links elections in Guatemala to elections in the United States, one becomes an instant expert on Guatemalan affairs, or Latin American affairsknowledge or training in the International Relations/Comparative Politics field is not needed. Therefore, there is no need for regionalists in political science anymore because the modus operandi is to create "thin theory" as will be discussed below.

\footnotetext{
6 "No study has established that the use of large-n methods produces more knowledge per hour of research than qualitative methods. Nor has a deductive case been advanced explaining why quantitative methods should provide stronger, cheaper, or easier tests than qualitative methods. Yet, a presumption in favor of quantitative over qualitative methods has appeared in the last few years. It is seen, for example, in the decision of many political science departments to require courses in quantitative but not qualitative methods in their $\mathrm{PhD}$ programs, even though published political science research is divided about equally between quantitative and qualitative methods." (Evera, 3)
} 


\section{Comparative Democratization: Thick or Thin Theory?}

Comparative democratization as a subfield in political science has found it difficult to progress given the increased focus on what Coppedge calls "thin theory" versus "thick theory": "Thick approaches lend themselves to rich understanding of specific events; thin approaches lend themselves to hypothesis testing and generalization". He further clarifies:

I argue that existing quantitative indicators are adequate for some purposes but that we cannot measure democracy much better until we thicken the concept that we are operationalizing to take multiple dimensions of democracy into account. (Coppedge, 2012: 6)

It is important here to indicate that not only is there contestation about the Middle East as a region, the definition of democracy and what democratic transition entails, is also contentious.

Unfortunately one of the most difficult challenges in studying democratization has been reaching agreement on what "democracy" is. In fact, W.B. Gallie once argued that democracy is on of the best examples of an essentially contested concept. (Coppedge, 2012:11)

According to Coppedge, an example of thick concepts on democratization is Cardoso and Faletto in 1971 with the Dependencia theory. (Coppedge, 2012: 22)

Thus research in comparative democratization is so contested that Coppedge realizes:

When qualitative and quantitative analysts say "democracy", they literally mean different things. Strictly speaking, research on the causes of thin democracy, speak only to the research on thin democratization; research on the causes of thick democracy has relevance for a longer and richer theoretical tradition. (Coppedge, 2012: 23)

Comparative democratization as a subfield is also in an area where "generalization" is on a path of self-destruction as Coppedge highlights. Although the definition of democracy is contentious many data sets have reduced it to measurable variables: e.g. Polity IV, and Freedom House. Coppedge here emphasizes that: 1) it is taken for granted what democratization means according to research methodology, 2) in order to run "generalizable" theory, researchers risk the fact that this theory is "thin", i.e. limited in explanation/ prediction capabilities because of its methodological constraints. 


\section{The Effect of the Seismic Shift on the MENA region research:}

\section{A. The Arab Barometer}

One of the data sets that exemplify thin theory is the Arab Barometer data. The paper written by Beissinger, Jamal, and Mazur, titled: "Who Participated in the Arab Spring? A Comparison of Egyptian and Tunisian Revolutions", explains how they "measured" piety in Tunisia and Egypt: "to capture levels of piety, we constructed a fifteen point scale measuring the frequency with which individuals perform five behaviors associated with religiosity, including reading the Quran or Bible and praying." (Beissinger, Jamal, and Mazur, 13) The questioning of the people's practice of the faith is so culturally and politically loaded that responses to those questions risk evaluatory inaccuracies. Whether we consider colonization or the forced nature of secularization post- colonization, people from all socioeconomic levels of society are extremely aware of the sensitivity of such questions. Even the illiterate would be weary to respond to such questions. This weariness is derived from the colonial and post-colonial experience that entails apologetic behavior on the part of indigenous peoples. Without getting into further historical detail (which is exactly what Coppedge thinks is of prime significance), it is obvious that the questions in the survey were inadequate culturally and historically. The research contradicts itself by stating that: "Though we have no direct evidence on the religious character of civil society associations, it is reasonable to infer that many were religious in orientation; Islamic charitable societies and religious movements like the Muslim Brotherhood in Egypt and Ennahda in Tunisia exemplify this tendency." (Beissinger, Jamal, and Mazur, n.d.: 16) That is to say they realize that gathering information about religious practices, did not provide them with direct evidence on the religious character of civil society.

The cited paper also indicates that according to their survey, participants in the revolution in Egypt demonstrated "primarily about the economy, with demands for civil and political freedoms ranking relatively low". (Beissinger, Jamal, and Mazur, n.d.: 20-21). How does this data and research reconcile the fact that Wael Ghoneim ${ }^{7}$ was deemed as the symbol of the revolution because of his Facebook page titled: We are all Khaled Saeed, a young student who was brutally attacked in public by the police till he died, then the government forced forensics to say that he died because of a drug overdose, a year before the revolution.

Again another example of the study contradicting itself in terms of findings, the co-authored paper starts first by stating that: "participants in the Egyptian Revolution were disproportionately middle-aged, middle class,

\footnotetext{
${ }^{7}$ Wael Ghoneim is a political activist who also worked for Google as a computer engineer.
} 
professional, and religious" (Beissinger, Jamal, and Mazur, n.d: 4) later on they state: "Similarly, religiosity does not appear to be systemically related to protest participation" (Beissinger, Jamal, and Mazur, n.d: 13).

Again a few pages later the authors state: "Though we have no direct evidence on the religious character of civil society associations, it is reasonable to infer that many were religious in orientation; Islamic charitable societies and religious movements like the Muslim Brotherhood in Egypt and Ennahda in Tunisia exemplify this tendency. (Beissinger, Jamal, and Mazur, n.d: 16)

The paper's attempt at defining who the participants were in the Egyptian revolution, however, did detect some important facts: The data reflects on the participants' social classes and whether they belonged to civil society associations, and those questions are easier to answer in survey, then the questions referred to earlier concerning piety and faith.

\section{B. Marc Lynch's "The Arab Uprisings Explained"}

In Marc Lynch's edited volume, he introduces the book by emphasizing the difficulty with predicting the Arab Spring. ${ }^{8}$ Lynch also points out that "pacting" theory; a theory utilized to explain democratic transitions in Latin America and Southern Europe is not applicable/generalizable to the MENA region. (Lynch, 5)

The theories of democratic transition then get fleshed out by Daniel Brumberg who clearly states that:

"scholars of the Arab world are suffering their own paradigm crisis. Surprised by mass political rebellions that few saw coming, beyond asking hard questions about the theories that had informed our work, we are once again trying to decide just how our geographic area fits into the wider field of comparative politics itself." (Lynch, 29)

What is central to Brumberg's chapter and to this paper namely is that identity politics and cultural influences that affected the uprisings. Trying to strike a balance between theoretically generalizable and therefore relevant, and also account for cultural factors that affected those uprisings is extremely difficult if not impossible (Lynch, 30) Therefore as regionalists what Lynch and Brumberg seem to emphasize is that the pressure to produce grand theory and to generalize has left regionalists in a difficult paradigmatic plight, where at best they would be able to tackle "mid-range" theory, i.e. there is a struggle

\footnotetext{
8 "Political scientists focused on the Middle East completely missed the potential for mobilization" (Lynch, 5)

"But few predicted the precise nature of the eruption. This was not because of a failure to observe the trends, but rather a tendency to accord inadequate weight to these discordant trends or else an entirely appropriate scholarly caution in the face of popular and activist enthusiasm." (Lynch, 6)
} 
between working with the specificity of identity, culture, religion, and being able to generalize about the MENA region as a whole. ${ }^{9}$

Brumberg clearly states:

"Indeed, precisely because the evolution of semi autocracies is always shaped to an extent by local logics, institutions, and cultures, relying on universal models invites empirical and conceptual shoehorning of the more particular into the more universal. Shoehorning is bound to loom most forcefully the more we stretch theories to cover regions that are vastly different." (Lynch, 44)

Upon applying current methodology to the "Arab Spring", the authors of the edited volume emphasize the danger of "shoehorning" regions to fit in the larger schema of generalizable theory. As previously discussed in Gardner's critique; researchers are "sacrificing political relevance at the alter of methodology".

\section{Shibley Telhami's "Identity and Foreign Policy in the Middle East"}

On a different plane, not only has methodology hampered progress in certain subfields of political science, but also the theoretical divides have influenced how studying the issue of identity and culture in the MENA region is conducted.

According to Telhami's edited volume on identity in the Middle East:

The tendency among scholars of Middle Eastern politics to focus on identitybased movements led to the field's self-exclusion from broader theoretical debates. Because the content of these identity-based movements was particular to the region, the region appeared to be unique. Systemic-oriented scholars, by contrast, could build an analytic bridge between the Middle East and theory-building. In addition, rationalists' precepts provided a haven from the sometimes latent orientalism and ethnocentrism that characterized scholarship on the region. Rational-choice theories presumed that Arab leaders were like their counterparts elsewhere, and that their base interests and instincts were driven by the familiar, fundamental goals of power, security, and survival. The view that Middle Eastern populations were somehow irrational and were driven into the streets in acts of self-destruction was now replaced by the view that social mobilization could be affected by on-standing grievances and collectiveaction problems familiar to students of protest politics. Although this move toward rationalism had the effect of denying any explanatory significance to culture, religion, and identity politics, it was welcome in a field that frequently made unwarranted, reified, and non-falsifiable claims regarding Arab or Middle Eastern culture." (Telhami, 3-4)

\footnotetext{
${ }^{9}$ In post-transition theory there is "a striking incapacity to theorize the role of local cultures, political logics, or ideologies in either regime change or stasis” (Lynch, 31)
} 
On the other hand Telhami recognizes the challenge of dealing with identity formation in the Middle East, because of how "fluid" identity formation is in the region and I would argue in all regions and cultures identity formation and cultural composition is "fluid".

The edited volume is an attempt to look at identity and foreign policy utilizing one of the three international relations approaches: institutionalism, constructivism, and liberalism. (Telhami, 169) The book concludes that identity politics and foreign policy making in the Middle East could not successfully or thoroughly be analyzed using one of the single approaches mentioned above. In Telhami's first remark though, it is clear that there is a struggle in using one of those approaches in order to "bridge" the divide between regional research and theory building, i.e. the ability to engage in more generalizable theory.

\section{Conclusion}

This paper analyzed literature from many fields of specialization and many levels of analysis, from the general to the more specifically focused on the region. This variation was intended to express the methodological shift and how it has influenced/affected other fields/subfields of the social sciences.

The current ability to monopolize journal publications, conferences, and the growth of the field itself, will eventually lead to the demise and neglect of regionalism let alone a country specific analysis. Methodological rigidity and the focus on grand theory building will have very limited insights or the ability to predict political phenomena. This forecast will bring forth stillborn regional studies, which will ultimately affect the MENA region as an area of study, let alone the study of culture and historical context. 


\section{Bibliography:}

Beissinger, Mark, Amaney Jamal, and Kevin Mazur, Who Participated in the Arab Spring? A Comparison of Egyptian and Tunisian Revolutions, https://www.researchgate.net/publication/256026784_Who_Participated_ in_the_Arab_Spring_A_Comparison_of_Egyptian_and_Tunisian_ Revolutions

Coppedge, Michael, Democratization and Research Methods (Cambridge University Press, 2012)

Evera, Steven Van, Annual Report for the MIT Security Studies Program 20092010.

Gardner, James A., Stop Me Before I Quantify Again: The Role of Political Science in the Study of Election Law, (Digital Commons at Loyola Marymount University and Loyola Law School: digitalcommons.lmu. edu/llr/vol.32/iss $4 / 11)$

Lynch, Marc, (edited), The Arab Uprisings Explained: New Contentious Politics in the Middle East, (Columbia University Press, 2014)

Telhami, Shibley, and Michael Barnett (edited), Identity and Foreign Policy in the Middle East, (Cornell University Press, 2002). 
